\title{
МАТЕМАТИЧЕСКОЕ ОПИСАНИЕ ПРОЦЕССА ГАЗИФИКАЦИИ ТВЕРДОГО ТОПЛИВА В ФИКСИРОВАННОМ СЛОЕ: 1. ЧИСЛЕННЫЕ РЕЗУЛЬТАТЫ ТЕРМОХИМИЧЕСКОЙ ПЕРЕРАБОТКИ ТОРФА В ПАРОКИСЛОРОДНОЙ СМЕСИ ПОД ДАВЛЕНИЕМ 3 МПа
}

\author{
Б.Б. Рохман, докт. техн. наук \\ Институт возобновляемой энергетики НАН Украины, \\ 04070, г. Киев, ул. Андреевская 19
}

Построена система параболических уравнений, описывающая нестационарный процесс аэродинамики, тепломассообмена и химического реагирования твердого топлива (частии торфа или биомассы) в парокислородной смеси в неподвижном слое с учетом конвективного теплообмена между газом и дисперсной фазой, радиационно-кондуктивного теплопереноса твердой фазы, лучистого и кондуктивного теплообмена частии слоя со стенкой реактора, гетерогенных и гомогенных химических реакиий, сил тяжести и аэродинамического сопротивления. На основании полученной системы уравнений разработаны алгоритм и программа, с использованием которой получена детальная информация о распределении основных параметров рабочего процесса термохимической переработки торфа под давлением 3 МПа в зависимости от времени для двух вариантов: при отнотении массовых долей в парокислородной смеси $\mathrm{H}_{2} \mathrm{O} / \mathrm{O}_{2}=70 / 30$ и $\mathrm{H}_{2} \mathrm{O} / \mathrm{O}_{2}=40 / 60$. Проведен сравнительный анализ этих вариантов. Показано, что: а) в первом варианте $\mathrm{H}_{2} \mathrm{O} / \mathrm{O}_{2}=70 / 30$, где в зоне максимальных тепловыделений температура частии торфа оказывается ниже, чем температура начала деформации золь, организуется режим газификации с твердым шлакоудалением. Во втором $-\mathrm{H}_{2} \mathrm{O} / \mathrm{O}_{2}=40 / 60$ за счет высокой интенсификации проиесса температура твердой фазы в окислительной зоне значительно превышает температуру жидкоплавкого состояния золы, что позволяет организовать режим газификачии торфа с устойчивым вытеканием жидкого илака из газогенератора; б) вариант 1 характеризуется высоким содержанием балласта в синтетическом газе $\mathrm{CO}_{2}=22,4 \%$ и $\mathrm{H}_{2} \mathrm{O}=10,3 \%$ и сравнительно низкой объемной долей горючей части - $\mathrm{CO}+\mathrm{H}_{2}=67,4 \%$, по сравнению с вариантом $2-\mathrm{CO}_{2}=1,5-2 \%, \mathrm{H}_{2} \mathrm{O}=0,1-$ $0,6 \%$ и $\mathrm{CO}+\mathrm{H}_{2}=98 \%$. Библ. 1, табл. 1, рис.10.

Ключевые слова: неподвижный слой, торф, теплопроводность, парокислородная газификация, кондуктивный, радиационный, температура.

\section{MATHEMATICAL DESCRIPTION OF THE SOLID FUEL GASIFICATION PROCESS IN A FIXED BED:}

\section{NUMERICAL RESULTS OF THERMAL-CHEMICAL PROCESSING OF PEAT IN A VAPOR- OXYGEN MIXTURE UNDER A PRESSURE OF 3 MPa}

\section{B. Rokhman, doctor of technical sciences}

Renewable Energy Institute of NAS of Ukraine,

02094, 20A, Hnata Khotkevicha Str., Kyiv, Ukraine

With the help of the developed two-dimensional model presented in the first part of this work, which includes interfacial convective heat transfer, radiation-conductive heat transfer of the solid phase, radiant and conductive heat transfer of the fixed bed with the reactor wall, heterogeneous and homogeneous chemical reactions, gravity and aerodynamic resistance, the non-stationary gasification of Shubarkol long-flame coal in a steam-oxygen mixture under a pressure of 3 MPa in a fixed bed with solid slag removal at a ratio of mass fractions of gas components $\mathrm{H}_{2} \mathrm{O} / \mathrm{O}_{2}=72 / 28$ was numerically investigated. It is shown: 1) in this mode, the temperature of coke-ash particles does not exceed $1000{ }^{\circ} \mathrm{C}$ due to the prevalence of heat generation of exothermic reactions $\mathrm{C}+\mathrm{O}_{2}=\mathrm{CO}_{2}$, $\mathrm{C}+0,5 \mathrm{O}_{2}=\mathrm{CO}, \mathrm{CO}+0,5 \mathrm{O}_{2}=\mathrm{CO}_{2}$ and $\mathrm{H}_{2}+0,5 \mathrm{O}_{2}=\mathrm{H}_{2} \mathrm{O}$ over the heat absorption of endothermic reactions $\mathrm{C}+\mathrm{CO}=2 \mathrm{CO}$ and $\mathrm{C}+\mathrm{H}_{2} \mathrm{O}=\mathrm{CO}+\mathrm{H}_{2}$ due to the high concentration of water vapor in the gas mixture. Therefore, calorie and quality of the generator gas (at the time $\tau=260 \mathrm{~s}$ (by volume): $\mathrm{CO}=16,4 \%, \mathrm{H}_{2}=44,6 \%, \mathrm{CO}_{2}=27,6 \%, \mathrm{CH}_{4}=10,1 \%$ and $\mathrm{C}_{6} \mathrm{H}_{6}=1,16 \%$ ) is significantly inferior to the synthetic gas obtained with the ratio of mass fractions of gaseous components $\mathrm{H}_{2} \mathrm{O} / \mathrm{O}_{2}=40 / 60$ ( $\tau=280 \mathrm{c}: \mathrm{CO}=65 \%, \mathrm{H}_{2}=25,6 \%$, $\mathrm{CO}_{2}=3,8 \%, \mathrm{CH}_{4}=5 \%$ and $\mathrm{C}_{6} \mathrm{H}_{6}=0,57 \%$ ) [1];2) To eliminate overheating of the grate due to the low height of the slag pad, due to low ash content of coal 3-9\%, it is recommended to add waste ash to the initial fuel, which will increase the height of the protective inert bed. 3) the calculated composition of the synthetic gas at $\tau=260 \mathrm{~s}$ is in good agreement with the literature data given in [2]: $\mathrm{CO}=12-21 \%, \mathrm{H}_{2}=37-41 \%, \mathrm{CO}_{2}=27-34 \%$ and $\mathrm{CH}_{4}=10-13,5 \%$. Ref. 1, tab. 1, fig. 10.

Keywords: fixed bed, coal, thermal conductivity, steam-oxygen gasification, conductive, radiation, temperature. 


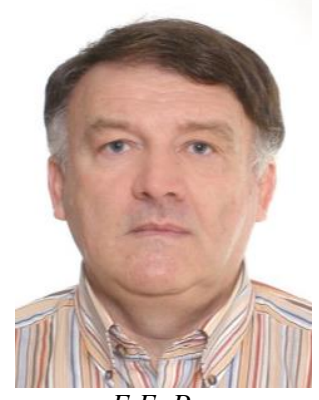

Б.Б. Рохман

B. Rokhman
Сведения об авторе: ведущий научный сотрудник Института угольных энерготехнологий НАН Украины, доктор технических наук. Биографические данные Рохмана Б.Б. размещены в известных мировых изданиях "Who's Who in Science and Engineering" и "2000 Outstanding Intellectuals of the 21st Century".

Образование: Новочеркасский политехнический институт.

Научная сфера: Математическое моделирование аэро-динамики, тепломассообмена и химического реагирования поли-дисперсного ансамбля твердого топлива в камерных и слоевых топках, в реакторах с циркулирующим кипящим слоем и в кипящем слое.

Публикации: более 90 научных работ, из них 27 работ содержатся в наукометрической базе Scopus и 4 в наукометрической базе Web of Science.

ORCID: 0000-0002-1270-6102

Контакты: тел.: +38-044-425-53-77

e-mail: Brolene@yahoo.com
Author Information: the leading researcher of the Institute of Coal Energy Technologies of the NAS of Ukraine, Doctor of Technical Sciences. Biographical information of Rohman B.B. is published in well-known world directories "Who's Who in Science and Engineering" and "2000 Outstanding Intellectuals of the 21st Century".

Education: Novocherkassk Polytechnic Institute.

Research area: Mathematical modeling of aerodynamics, heat and mass transfer and chemical reaction of a polydisperse ensemble of solid fuel in chamber and layer furnaces, in reactors with a circulating fluidized bed and in the fluidized bed.

Publications: more than 90 scientific papers, 27 of them are contained in the science-based Scopus database and 4 in the science-based Web of Science database.

ORCID: 0000-0002-1270-6102

Contacts: phone: +38-044-425-53-77

e-mail: Brolene@yahoo.com

\section{Перечень используемых обозначений и сокращений:}

a - степень черноты частицы;

$A, N, O, S, V, W$ - массовые доли золы, азота, кислорода, серы, летучих веществ и влаги в твердом топливе;

B $\quad$ - расход, кг/ч;

C - концентрации газовых компонентов, (кмоль/м ${ }^{3}$ ) или массовая доля углерода в твердом топливе;

c $\quad$ - теплоемкость, кДж/(кг К $)$;

$D \quad$ - коэффициент диффузии, $\mathrm{m}^{2} / \mathrm{c}$;

$H$ - высота (м) или массовая доля водорода;

$h$ - коэффициент конвективного теплообмена, кДж/(c· $\left.\mathrm{M}^{2} \cdot \mathrm{K}\right)$;

$g$ - ускорение свободного падения, м/ $\mathrm{c}^{2}$;

$k$ - константа скорости реакции, м/c;

$m$ - масса, кг;

$P \quad$ - давление, $\mathrm{H} / \mathrm{M}^{2}$;

Индексы нижние:

$\begin{array}{ll}\text { ash } & - \text { зола; } \\ \text { A } & - \text { деформация золы; } \\ \text { bed } & - \text { слой; } \\ \text { B } & - \text { размягчение золы; } \\ \mathrm{C} & - \text { жидкоплавкое состояние золы } \\ & \text { или углерод; } \\ \mathrm{CO}, \mathrm{CO}_{2}, \mathrm{CH}_{4}, \mathrm{H}_{2} \mathrm{O}, & \text { - окись и двуокись углерода, метан, } \\ \mathrm{H}_{2}, \mathrm{C}_{2} \mathrm{H}_{2}, & \text { водяной пар, водород, ацетилен, } \\ \mathrm{CH}_{2,71311} \mathrm{O}_{0}, 982248 & \text { кислородосодержащее соединение; } \\ \mathrm{C}+\mathrm{O}_{2}, \mathrm{C}+0,5 \mathrm{O}_{2}, \mathrm{C} & - \text { гетерогенные реакции; } \\ +\mathrm{CO}_{2}, \mathrm{C}+\mathrm{H}_{2} \mathrm{O} & \\ \mathrm{CO}+\mathrm{O}_{2}, \mathrm{H}_{2}+\mathrm{O}_{2}, & - \text { гомогенные реакции; } \\ \mathrm{CO}+\mathrm{H}_{2} \mathrm{O}, \mathrm{CH}_{4}+ & \\ \mathrm{H}_{2} \mathrm{O} & - \text { конвективный теплообмен; } \\ \text { conv } & - \text { парокислородная смесь; } \\ \mathrm{H}_{2} \mathrm{O}+\mathrm{O}_{2} & \\ \text { Индексы верхние: } & \\ \text { cond - кондуктивный теплообмен; } \\ \text { daf } \quad \text { сухая беззольная масса; } \\ \text { w - поверхность; }\end{array}$

Введение. Проблемы поиска возобновляемых видов сырья и технологий их термохимической переработки для промышленности и энерге-
$Q \quad$ - тепловой эффект реакции (кДж/кмоль) или тепловой поток (кДж/(c· $\left.\left.{ }^{3}\right)\right)$;

$R$ - объемная доля компонента газовой смеси;

$r$ - скорость гомогенной реакции, кмоль/(м $\left.{ }^{3} \cdot \mathrm{c}\right)$;

- температура, ${ }^{\circ} \mathrm{C}$;

- скорость, м/с;

- аксиальная координата, м;

- диаметр частицы, м;

- порозность слоя;

- коэффициент теплопроводности,

кДж/(c·м К);

- кинематическая вязкость газа, $\mathrm{M}^{2} / \mathrm{c}$;

- молекулярная масса, кг/кмоль;

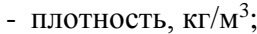

- время, с

- предэкспоненциальный множитель, $\mathrm{c}^{-1}$.
$\mathrm{CO}_{2} \rightarrow \mathrm{cm}, \mathrm{O}_{2} \rightarrow \mathrm{cm}, \quad$ - диффузия углекислого газа, кис$\mathrm{CO} \rightarrow \mathrm{cm}, \mathrm{H}_{2} \mathrm{O} \rightarrow \mathrm{cm}$, лорода, окиси углерода, водяного $\mathrm{H}_{2} \rightarrow \mathrm{cm}, \mathrm{C}_{2} \mathrm{H}_{2} \rightarrow \mathrm{cm}, \quad$ пара, водорода, ацетилена, метана и $\mathrm{CH}_{4} \rightarrow \mathrm{CM}$, $\mathrm{CH}_{2,71311} \mathrm{O}_{0,982248} \rightarrow \mathrm{cm} \quad$ в газовую смесь;

d - сухая масса;

g - газ;

$\max \quad-$ максимальное значение;

$\mathrm{p}-$ - частица;

$\mathrm{p} \rightarrow \mathrm{w} \quad-$ передача тепла от частиц к стенке;

volat - летучие вещества;

ф - - - - -

эф - - эффективный;

0 - начальные условия;

1,2

- варианты расчета.

$\operatorname{rad} \quad$ - лучистый теплообмен;

r - рабочая масса.

тического комплекса в настоящее время чрезвычайно актуальны. Одно из таких приоритетных направлений - газификация торфа в неподвиж- 
ном слое. По данным Международного торфяного общества (IPS, 1995) торфяные ресурсы в мире составляют более 400 млн. га, из которых $\sim 305$ млн. га эксплуатируются. Торф относится к молодым топливам и находится по своим энергетическим показателям между древесиной и бурым углем. Торф представляет собой продукты разложения растительных остатков и не успевших разложиться элементов растений, степень разложения которых растет с увеличением глубины его залегания. Различают верховой, низинный и смешанный виды торфа. В естественном состоянии торф является сильно обводненным, поэтому требуется его предварительная сушка. В воздушно-сухом состоянии влажность торфа составляет $15-25 \%$. Отметим, что в торфе содержится значительное количество минеральных веществ, которые существенно влияют на процесс газификации. В среднем элементный состав торфа можно представить как: 3,4-9,4 \% водорода, 54-60 \% углерода, 0,5-3,0 \% азота, 28,5-39,5 \% кислорода, $0,1-1,5 \%$ серы.

В первой части статьи представлено математическое описание и численное исследование нестационарного процесса парокислородной газификации частиц торфа под давлением 3 МПа в фиксированном слое $\left(C_{\phi}^{\mathrm{r}}=13,52 \%, C_{\text {volat }}^{\mathrm{r}}=\right.$ $=11,94 \%, S^{\mathrm{r}}=0,13 \%, \quad H^{\mathrm{r}}=2,7 \%, O^{\mathrm{r}}=$ $=15,64 \%, N^{\mathrm{r}}=1,13 \%, W^{\mathrm{r}}=48,5 \%$, $A^{\mathrm{r}}=6,44 \%, V^{\mathrm{daf}}=70 \%, t_{\mathrm{A}}=1140{ }^{\circ} \mathrm{C}$, $\left.t_{\mathrm{B}}=1280{ }^{\circ} \mathrm{C}, t_{\mathrm{C}}=1350{ }^{\circ} \mathrm{C}\right)$. Здесь рассматривается режим термохимической переработки сухого торфа при его одноразовой загрузке в газогенератор, где рабочий процесс характеризуется изменяющимися во времени профилями температур и концентраций двухфазной среды в слое.

На рис. 1 приведена схема газификации частиц торфа в неподвижном слое в парокислородной смеси. Рабочий процесс в газогенераторе, исходя из изменений, претерпеваемых торфом на различных стадиях термохимической переработки, можно условно разделить на четыре зоны. Шлаковая подушка (поз. 2) формируется из частиц золы, образующихся за счет горения и газификации исходного угля. Эта зона защищает под реактора от перегрева. Окислительная зона (поз. 3) включает в себя две области. В первой из них, где большая часть кислорода в очень узком интервале слоя интенсивно расходуется на конверсию углерода и догорание продуктов газификации $\mathrm{CO}$ и $\mathrm{H}_{2}$, температуры газа и частиц достигают максимальных значений. На втором участке (окислительно-восстановительная область реаги- рования) теплопоглощение эндотермических реакций $\mathrm{C}+\mathrm{CO}_{2}=2 \mathrm{CO}, \mathrm{C}+\mathrm{H}_{2} \mathrm{O}=\mathrm{CO}+\mathrm{H}_{2}$ превалирует над тепловыделением экзотермических реакций $\mathrm{C}+\mathrm{O}_{2}=\mathrm{CO}_{2}, \quad \mathrm{C}+0,5 \mathrm{O}_{2}=\mathrm{CO}, \quad \mathrm{CO}+0,5 \mathrm{O}_{2}=\mathrm{CO}_{2} \quad$ и $\mathrm{H}_{2}+0,5 \mathrm{O}_{2}=\mathrm{H}_{2} \mathrm{O}$, вследствие чего происходит резкое падение температур газа и частиц и концентрации $\mathrm{O}_{2}$. Далее процесс газификации торфа плавно переходит в бескислородную восстановительную зону (поз. 4), которая имеет значительно большую протяженность по сравнению с окислительной областью из-за малых скоростей гетерогенных восстановительных реакций, обусловленных низким уровнем температур дискретной фазы. В четвертой зоне (поз. 5) сухие частицы торфа нагреваются бескислородной газовой смесью за счет межфазного конвективного теплообмена и радиационно-кондуктивного теплопереноса в твердой фазе, что обеспечивает выход из исходного топлива летучих веществ, которые смешиваются с газовой средой, выходящей из третьей зоны, тем самым формируя генераторный газ на выходе из установки.

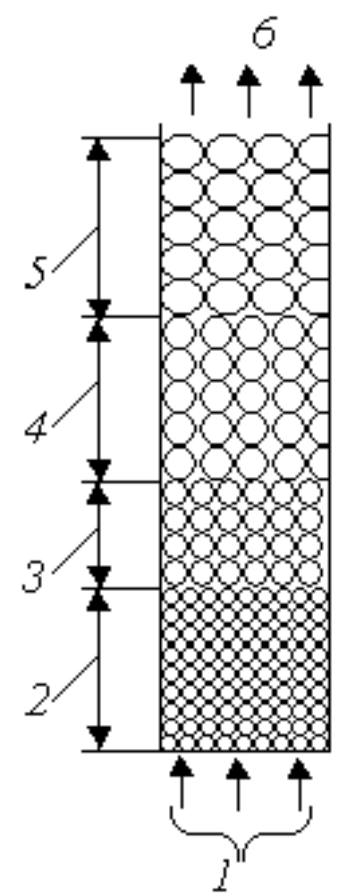

Рис. 1. Схема парокислородной газификации торфа в фиксированном слое: 1 - парокислородная смесь; 2 - шлаковая подушка; 3 - зона окисления; 4 - зона газификации;

5 - зона пиролиза; 6 - выход синтетического газа.

Fig. 1. Scheme of steam-oxygen gasification of peat in a fixed bed: 1 - steam-oxygen mixture; 2 - slag pad; 3 -oxidation zone; 4 - gasification zone; 5 - pyrolysis zone; 6 - syngas outlet.

Постановка задачи. Предлагаемая модель базируется на следующих основных предпосылках: 1) процесс нестационарный; 2) газовая смесь в реакторе состоит из кислорода, диоксида и оксида углерода, метана, водяного пара, водорода и 
ацетилена; 3) дисперсная фаза формируется из монодисперсных частиц сферической формы; 4) выход летучих веществ приводит к понижению плотности твердой фазы, а протекание гетерогенных реакций горения и газификации на поверхности частиц - к уменьшению их размера; 5) усадка неподвижного слоя за счет конверсии фиксированного углерода не учитывается; 6) газ движется в режиме идеального вытеснения; 7) стехиометрическая схема реакций включает в себя четыре гетерогенные реакции:

$$
\begin{aligned}
\mathrm{C}+\mathrm{O}_{2}=\mathrm{CO}_{2}, \mathrm{C}+0,5 \mathrm{O}_{2} & =\mathrm{CO}, \mathrm{C}+\mathrm{CO}_{2}=2 \mathrm{CO} \text { и } \\
\mathrm{C}+\mathrm{H}_{2} \mathrm{O} & =\mathrm{CO}+\mathrm{H}_{2}
\end{aligned}
$$

и пять гомогенных:

$$
\mathrm{CH}_{2,71311} \mathrm{O}_{0,982248} \rightarrow 0,211773 \mathrm{CO}+
$$

$0,134764 \mathrm{CO}_{2}+0,333524 \mathrm{CH}_{4}+0,162893 \mathrm{C}_{2} \mathrm{H}_{2}+$ $0,0256683 \mathrm{H}_{2}+0,500946 \mathrm{H}_{2} \mathrm{O}, \mathrm{CO}+0,5 \mathrm{O}_{2}=\mathrm{CO}_{2}$,

$\mathrm{H}_{2}+0,5 \mathrm{O}_{2}=\mathrm{H}_{2} \mathrm{O}, \mathrm{CO}+\mathrm{H}_{2} \mathrm{O}=\mathrm{CO}_{2}+\mathrm{H}_{2}$ и

$$
\mathrm{CH}_{4}+\mathrm{H}_{2} \mathrm{O}=\mathrm{CO}+3 \mathrm{H}_{2} \text {. }
$$

В стехиометрической схеме реакций летучие торфа представлены формулой кислородосодержащего соединения $\mathrm{CH}_{2,71311} \mathrm{O}_{0,982248}$, которое при нагреве разлагается на газовые компоненты $\mathrm{CO}$, $\mathrm{CO}_{2}, \mathrm{CH}_{4}, \mathrm{C}_{2} \mathrm{H}_{2}, \mathrm{H}_{2}$ и $\mathrm{H}_{2} \mathrm{O}$ согласно первой реакции в (2).

Слой прогревается высокотемпературной смесью дымовых газов и воздуха до достижения температуры воспламенения частиц (более 600 $\left.{ }^{\circ} \mathrm{C}\right)$, расположенных в узкой области, примыкающей к поду. Этот момент принят за начало отсчета $\tau=0$. Далее происходит отключение теплоносителя и подача вместо него парокислородной смеси с температурой $t_{\mathrm{H}_{2} \mathrm{O}+\mathrm{O}_{2}}=450{ }^{\circ} \mathrm{C}$.

Основные уравнения. Система уравнений, описывающая аэродинамику и физикохимические процессы в плотном слое газификатора может быть представлена в следующем виде:

1. Уравнение неразрывности для кислорода

$$
\begin{aligned}
\frac{\partial C_{\mathrm{O}_{2}}}{\partial \tau}+\frac{\partial\left(u_{\mathrm{g}} C_{\mathrm{O}_{2}}\right)}{\partial z}=\frac{\partial}{\partial z}[ & \left.D_{\mathrm{O}_{2} \rightarrow \mathrm{cm}} \frac{\partial C_{\mathrm{O}_{2}}}{\partial z}\right]-\frac{6\left(k_{\mathrm{C}+\mathrm{O}_{2}}+k_{\mathrm{C}+0.5 \mathrm{O}_{2}}\right) C_{\mathrm{O}_{2}}^{\mathrm{w}}(1-\varepsilon)}{\delta}- \\
& -0,5 r_{\mathrm{CO}+\mathrm{O}_{2}}-0,5 r_{\mathrm{H}_{2}+\mathrm{O}_{2}} .
\end{aligned}
$$

2. Уравнение неразрывности для диоксида углерода

$$
\begin{aligned}
\frac{\partial C_{\mathrm{CO}_{2}}}{\partial \tau}+\frac{\partial\left(u_{\mathrm{g}} C_{\mathrm{CO}_{2}}\right)}{\partial z}=\frac{\partial}{\partial z}[ & \left.D_{\mathrm{CO}_{2} \rightarrow \mathrm{cm}} \frac{\partial C_{\mathrm{CO}_{2}}}{\partial z}\right]+\frac{6\left(k_{\mathrm{C}_{\mathrm{O}}} C_{\mathrm{O}_{2}}-k_{\mathrm{C}_{\mathrm{CO}} C_{2}} C_{\mathrm{CO}_{2}}^{\mathrm{w}}\right)(1-\varepsilon)}{\delta}+r_{\mathrm{CO}+\mathrm{O}_{2}}+ \\
& +r_{\mathrm{CO}+\mathrm{H}_{2} \mathrm{O}}+0,134764 r_{\mathrm{CH}_{2,71311} \mathrm{O}_{0,982248} \rightarrow .}
\end{aligned}
$$

3. Уравнение неразрывности для окиси углерода

$$
\begin{aligned}
\frac{\partial C_{\mathrm{CO}}}{\partial \tau}+\frac{\partial\left(u_{\mathrm{g}} C_{\mathrm{CO}}\right)}{\partial z}= & \frac{\partial}{\partial z}\left[D_{\mathrm{CO} \rightarrow \mathrm{cm}} \frac{\partial C_{\mathrm{CO}}}{\partial z}\right]+\frac{6\left[2\left(k_{\mathrm{C}^{2} 0.5 \mathrm{O}_{2}} C_{\mathrm{O}_{2}}^{\mathrm{w}}+k_{\mathrm{C}^{+\mathrm{CO}_{2}}} C_{\mathrm{CO}_{2}}^{\mathrm{w}}\right)+k_{\mathrm{C}+\mathrm{H}_{2} \mathrm{O}} C_{\mathrm{H}_{2} \mathrm{O}}^{\mathrm{w}}\right](1-\varepsilon)}{\delta}- \\
& -r_{\mathrm{CO}+\mathrm{O}_{2}}-r_{\mathrm{CO}+\mathrm{H}_{2} \mathrm{O}}+r_{\mathrm{CH}_{4}+\mathrm{H}_{2} \mathrm{O}}+0,211773 r_{\mathrm{CH}_{2,71311} \mathrm{O}_{0,982248} \rightarrow} \cdot
\end{aligned}
$$

4. Уравнение неразрывности для метана

$$
\frac{\partial C_{\mathrm{CH}_{4}}}{\partial \tau}+\frac{\partial\left(u_{\mathrm{g}} C_{\mathrm{CH}_{4}}\right)}{\partial z}=\frac{\partial}{\partial z}\left[D_{\mathrm{CH}_{4} \rightarrow \mathrm{cm}} \frac{\partial C_{\mathrm{CH}_{4}}}{\partial z}\right]-r_{\mathrm{CH}_{4}+\mathrm{H}_{2} \mathrm{O}}+0,333524 r_{\mathrm{CH}_{2,7131} \rho_{0,982248} \rightarrow} .
$$

5. Уравнение неразрывности для водяного пара

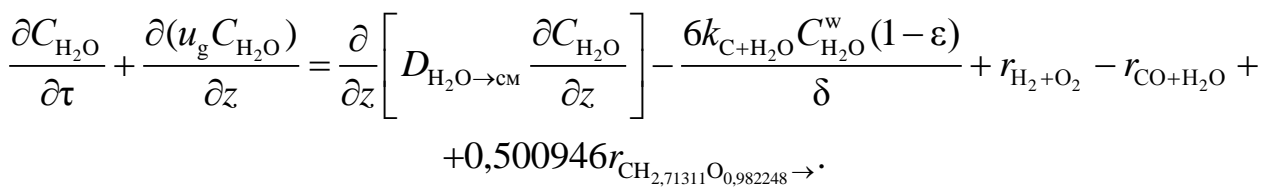

6. Уравнение неразрывности для водорода

$$
\begin{gathered}
\frac{\partial C_{\mathrm{H}_{2}}}{\partial \tau}+\frac{\partial\left(u_{\mathrm{g}} C_{\mathrm{H}_{2}}\right)}{\partial z}=\frac{\partial}{\partial z}\left[D_{\mathrm{H}_{2} \rightarrow \mathrm{cm}} \frac{\partial C_{\mathrm{H}_{2}}}{\partial z}\right]+\frac{6 k_{\mathrm{C}+\mathrm{H}_{2} \mathrm{O}} C_{\mathrm{H}_{2} \mathrm{O}}^{\mathrm{w}}(1-\varepsilon)}{\delta}-r_{\mathrm{H}_{2}+\mathrm{O}_{2}}+r_{\mathrm{CO}+\mathrm{H}_{2} \mathrm{O}}+3 r_{\mathrm{CH}_{4}+\mathrm{H}_{2} \mathrm{O}}+ \\
+0,0256683 r_{\mathrm{CH}_{2,71311} \mathrm{O}_{0,982248} \rightarrow} \cdot
\end{gathered}
$$

7. Уравнение неразрывности для ацетилена

$$
\frac{\partial C_{\mathrm{C}_{2} \mathrm{H}_{2}}}{\partial \tau}+\frac{\partial\left(u_{\mathrm{g}} C_{\mathrm{C}_{2} \mathrm{H}_{2}}\right)}{\partial z}=\frac{\partial}{\partial z}\left[D_{\mathrm{C}_{2} \mathrm{H}_{2} \rightarrow \mathrm{cm}} \frac{\partial C_{\mathrm{C}_{2} \mathrm{H}_{2}}}{\partial z}\right]+0,162893 r_{\mathrm{CH}_{2,7131} \rho_{0,982248} \rightarrow} .
$$


8. Уравнение неразрывности для кислородосодержащего соединения $\mathrm{CH}_{2,71311} \mathrm{O}_{0,982248}$

$$
\begin{aligned}
& \frac{\partial C_{\mathrm{CH}_{2,71311} \mathrm{O}_{0,982248}}}{\partial \tau}+\frac{\partial\left(u_{\mathrm{g}} C_{\mathrm{CH}_{2,71311} \mathrm{O}_{0,982248}}\right)}{\partial z}=\frac{6(1-\varepsilon) m_{\mathrm{p} 0}\left(1-V_{\mathrm{d}}\right) V_{\mathrm{d}} A_{\mathrm{volat}} \exp \left[-\int_{0}^{\tau} A_{\mathrm{volat}} d \tau\right]}{\pi\left(1-V_{\mathrm{d}} \exp \left[-\int_{0}^{\tau} A_{\mathrm{volat}} d \tau\right]\right)^{2} \delta^{3} \mu_{\mathrm{CH}_{2,71311} \mathrm{O}_{0,982248}}}+ \\
& +\frac{\partial}{\partial z}\left[D_{\mathrm{CH}_{2,71311} \mathrm{O}_{0,982248} \rightarrow \mathrm{cm}} \frac{\partial C_{\mathrm{CH}_{2,71311} \mathrm{O}_{0,982248}}}{\partial z}\right]-r_{\mathrm{CH}_{2,71311} \mathrm{O}_{0,982248} \rightarrow} \text {. }
\end{aligned}
$$

9. Уравнение изменения диаметра частиц

$$
\frac{d \delta}{d \tau}=-\left[\left(k_{\mathrm{C}+\mathrm{O}_{2}}+2 k_{\mathrm{C}+0.5 \mathrm{O}_{2}}\right) C_{\mathrm{O}_{2}}^{\mathrm{w}}+k_{{\mathrm{C}+\mathrm{CO}_{2}}} C_{\mathrm{CO}_{2}}^{\mathrm{w}}+k_{\mathrm{C}+\mathrm{H}_{2} \mathrm{O}} C_{\mathrm{H}_{2} \mathrm{O}}^{\mathrm{w}}\right] \frac{2 \mu_{\mathrm{C}}}{\rho_{\mathrm{p}}} .
$$

10. Уравнение изменения плотности частиц

$$
\frac{d \rho_{\mathrm{p}}}{d \tau}=-\frac{\rho_{\mathrm{p} 0}\left(1-V_{\mathrm{d}}\right) V_{\mathrm{d}} A_{\mathrm{volat}} \exp \left[-\int_{0}^{\tau} A_{\mathrm{volat}} d \tau\right]}{\left(1-V_{\mathrm{d}} \exp \left[-\int_{0}^{\tau} A_{\text {volat }} d \tau\right]\right)^{2}} .
$$

11. Уравнение сохранения количества движения газовой фазы

$$
\begin{gathered}
\frac{\partial\left(\rho_{\mathrm{g}} u_{\mathrm{g}}\right)}{\partial \tau}+\frac{\partial\left(\rho_{\mathrm{g}} u_{\mathrm{g}}^{2}\right)}{\partial z}=-\frac{\partial P_{\mathrm{g}}}{\partial z} \\
-g \rho_{\mathrm{g}}+\frac{\partial}{\partial z}\left[\rho_{\mathrm{g}} \eta_{\mathrm{g}} \frac{\partial u_{\mathrm{g}}}{\partial z}\right]-\frac{150 \eta_{\mathrm{g}} \rho_{\mathrm{g}}(1-\varepsilon)^{2} u_{\mathrm{g}}}{\delta^{2} \varepsilon^{3}}- \\
-\frac{1,75 \rho_{\mathrm{g}}(1-\varepsilon) u_{\mathrm{g}}^{2}}{\delta \varepsilon^{3}} .
\end{gathered}
$$

12. Уравнение теплового баланса частиц

$$
\begin{aligned}
& \rho_{\mathrm{p}}(1-\varepsilon) c_{\mathrm{p}} \frac{\partial t_{\mathrm{p}}}{\partial \tau}=\frac{\partial}{\partial z}\left[\lambda_{\text {э中 }} \frac{\partial t_{\mathrm{p}}}{\partial z}\right]+\left[\left(k_{\mathrm{C}+\mathrm{O}_{2}} Q_{\mathrm{C}+\mathrm{O}_{2}}+k_{\mathrm{C}+0,5 \mathrm{O}_{2}} Q_{\mathrm{C}+0,5 \mathrm{O}_{2}}\right) C_{\mathrm{O}_{2}}^{\mathrm{w}}-k_{{\mathrm{C}+\mathrm{CO}_{2}}} C_{\mathrm{CO}_{2}}^{\mathrm{w}} Q_{\mathrm{C}+\mathrm{CO}_{2}}-\right. \\
& \left.-k_{\mathrm{C}+\mathrm{H}_{2} \mathrm{O}} C_{\mathrm{H}_{2} \mathrm{O}}^{\mathrm{w}} Q_{\mathrm{C}+\mathrm{H}_{2} \mathrm{O}}-h_{\mathrm{conv}}\left(t_{\mathrm{p}}-t_{\mathrm{g}}\right)\right] \frac{6(1-\varepsilon)}{\delta}-Q_{\mathrm{p} \rightarrow \mathrm{w}}^{\mathrm{rad}}-Q_{\mathrm{p} \rightarrow \mathrm{w}}^{\mathrm{cond}}+ \\
& +\frac{(1-\varepsilon) c_{\mathrm{p}} t_{\mathrm{p}} \rho_{\mathrm{p} 0}\left(1-V_{\mathrm{d}}\right) V_{\mathrm{d}} A_{\text {volat }} \exp \left[-\int_{0}^{\tau} A_{\text {volat }} d \tau\right]}{\left(1-V_{\mathrm{d}} \exp \left[-\int_{0}^{\tau} A_{\text {volat }} d \tau\right]\right)^{2}} .
\end{aligned}
$$

13. Уравнение сохранения энергии несущей среды

$$
\begin{aligned}
& \quad \frac{\partial \rho_{\mathrm{g}} c_{\mathrm{g}} t_{\mathrm{g}}}{\partial \tau}+\frac{\partial\left(\rho_{\mathrm{g}} u_{\mathrm{g}} c_{\mathrm{g}} t_{\mathrm{g}}\right)}{\partial z}=\frac{\partial}{\partial z}\left[\lambda_{\mathrm{g}, 9 \phi} \frac{\partial t_{\mathrm{g}}}{\partial z}\right]+h_{\mathrm{conv}}\left(t_{\mathrm{p}}-t_{\mathrm{g}}\right) \frac{6(1-\varepsilon)}{\delta}+ \\
& +r_{\mathrm{CO}+\mathrm{O}_{2}} Q_{\mathrm{CO}+\mathrm{O}_{2}}+r_{\mathrm{H}_{2}+\mathrm{O}_{2}} Q_{\mathrm{H}_{2}+\mathrm{O}_{2}}+r_{\mathrm{CO}+\mathrm{H}_{2} \mathrm{O}} Q_{\mathrm{CO}+\mathrm{H}_{2} \mathrm{O}}+r_{\mathrm{CH}_{4}+\mathrm{H}_{2} \mathrm{O}} Q_{\mathrm{CH}_{4}+\mathrm{H}_{2} \mathrm{O}} .
\end{aligned}
$$

где эффективный коэффициент теплопроводно-

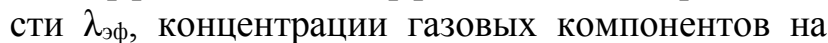
поверхности частицы $C_{\mathrm{O}_{2}}^{\mathrm{w}}, C_{\mathrm{CO}_{2}}^{\mathrm{w}}, C_{\mathrm{H}_{2} \mathrm{O}}^{\mathrm{w}}$ и $C_{\mathrm{CO}}^{\mathrm{w}}$, скорости реакций $r_{\mathrm{H}_{2}+\mathrm{O}_{2}}, \quad r_{\mathrm{CO}+\mathrm{H}_{2} \mathrm{O}}, r_{\mathrm{CO}+\mathrm{O}_{2}}$,
$r_{\mathrm{CH}_{4}+\mathrm{H}_{2} \mathrm{O}}$ и $r_{\mathrm{CH}_{2,7131} \rho_{0,982248}}$ и выхода летучих веществ из торфа определяются согласно [1].

Граничные условия на входе в слой $(z=0)$ для уравнений параболического типа (3)-(10), (13)-(15) находятся из выражений: 


$$
\begin{gathered}
\frac{\partial t_{\mathrm{p}}}{\partial z}=C_{\mathrm{CO}_{2}}=C_{\mathrm{CO}}=C_{\mathrm{CH}_{4}}=C_{\mathrm{H}_{2}}=C_{\mathrm{C}_{2} \mathrm{H}_{2}} \\
=C_{\mathrm{CH}_{2,7131} \mathrm{\rho}_{0,982248}}=0, C_{\mathrm{O}_{2}}=C_{\mathrm{O}_{2} 0}, C_{\mathrm{H}_{2} \mathrm{O}}= \\
C_{\mathrm{H}_{2} \mathrm{O} 0}, u_{\mathrm{g}}=u_{\mathrm{g} 0}, t_{\mathrm{g}}=t_{\mathrm{g} 0},
\end{gathered}
$$

на выходе из слоя $\left(z=H_{\text {bed }}\right)-$

$$
\begin{aligned}
& \frac{\partial t_{\mathrm{p}}}{\partial z}=\frac{\partial t_{\mathrm{g}}}{\partial z}=\frac{\partial C_{\mathrm{O}_{2}}}{\partial z}=\frac{\partial C_{\mathrm{CO}_{2}}}{\partial z}=\frac{\partial C_{\mathrm{CO}}}{\partial z}= \\
& \frac{\partial C_{\mathrm{CH}_{4}}}{\partial z}=\frac{\partial C_{\mathrm{H}_{2} \mathrm{O}}}{\partial z}=0, \frac{\partial C_{\mathrm{H}_{2}}}{\partial z}=\frac{\partial C_{\mathrm{C}_{2} \mathrm{H}_{2}}}{\partial z}= \\
& \frac{\partial C_{\mathrm{CH}_{2,7131} \mathrm{O}_{0,982248}}}{\partial z}=\frac{\partial u_{\mathrm{g}}}{\partial z}=0 .
\end{aligned}
$$

Результаты численных расчетов. Обсудим два варианта расчета парокислородной газификации частиц торфа плотностью $1450 \kappa \Gamma / \mathrm{m}^{3}$ в фиксированном слое порозностью $\varepsilon=0,4$, высотой слоя 1,61 м и диаметром 0,8 м под давлением $P_{\mathrm{g}}=3$ МПа. Вариант 1: $\mathrm{H}_{2} \mathrm{O} / \mathrm{O}_{2}=70 / 30$ $\left(B_{\mathrm{H}_{2} \mathrm{O}}=1568 \kappa \Gamma / \mathrm{ч}, B_{\mathrm{O}_{2}}=672 \kappa \mathrm{\kappa} / \mathrm{ч}\right), \delta=15 \mathrm{мm}$; вариант 2: $\mathrm{H}_{2} \mathrm{O} / \mathrm{O}_{2}=40 / 60\left(B_{\mathrm{H}_{2} \mathrm{O}}=1065 \mathrm{\kappa} / \mathrm{ч}\right.$,
$B_{\mathrm{O}_{2}}=1598$ кг $/$ ч), $\delta=30$ мм. Во всех вариантах температура парокислородной смеси $t_{\mathrm{H}_{2} \mathrm{O}+\mathrm{O}_{2}}=$ $=450{ }^{\circ} \mathrm{C}$ и скорость газа на входе в слой $u_{\mathrm{g} 0}=0,2 \mathrm{M} / \mathrm{c}$.

Окислительная зона $0<z<0,1036$ м $(\tau=30$ с) включает в себя два участка. В первом интервале $0<z<0,028$ м происходит интенсивная конверсия коксозольных частиц в парокислородной смеси за счет гетерогенных реакций $\mathrm{C}+\mathrm{O}_{2}=\mathrm{CO}_{2}, \mathrm{C}+0,5 \mathrm{O}_{2}=\mathrm{CO}, \mathrm{C}+\mathrm{CO}_{2}=2 \mathrm{CO}$ и $\mathrm{C}+\mathrm{H}_{2} \mathrm{O}$ $=\mathrm{CO}+\mathrm{H}_{2}$ и догорание продуктов газификации $\mathrm{CO}$ и $\mathrm{H}_{2}$ согласно реакциям $\mathrm{CO}+0,5 \mathrm{O}_{2}=\mathrm{CO}_{2}$ и $\mathrm{H}_{2}+0,5 \mathrm{O}_{2}=\mathrm{H}_{2} \mathrm{O}$. Здесь тепловыделение экзотермических реакций превалирует над теплопоглощением эндотермических реакций, вследствие чего температура $t_{\mathrm{p}}$ возрастает с $465{ }^{\circ} \mathrm{C}$ до максимального значения $818,5{ }^{\circ} \mathrm{C}$, содержание $\mathrm{O}_{2}$ и $\mathrm{H}_{2} \mathrm{O}$ в газовой смеси падает с $19,41 \%$ и $80,55 \%$ до $16,49 \%$ и $72,84 \%$, соответственно, объемные доли газовых компонентов $\mathrm{CO}_{2}, \mathrm{CO}$ и $\mathrm{H}_{2}$ повышаются и достигают следующих значений: $R_{\mathrm{CO}_{2}}=1,26 \%, R_{\mathrm{CO}}=5,38 \%$ и $R_{\mathrm{H}_{2}}=3,967 \%$ (рис. 2-5, кривые 1).
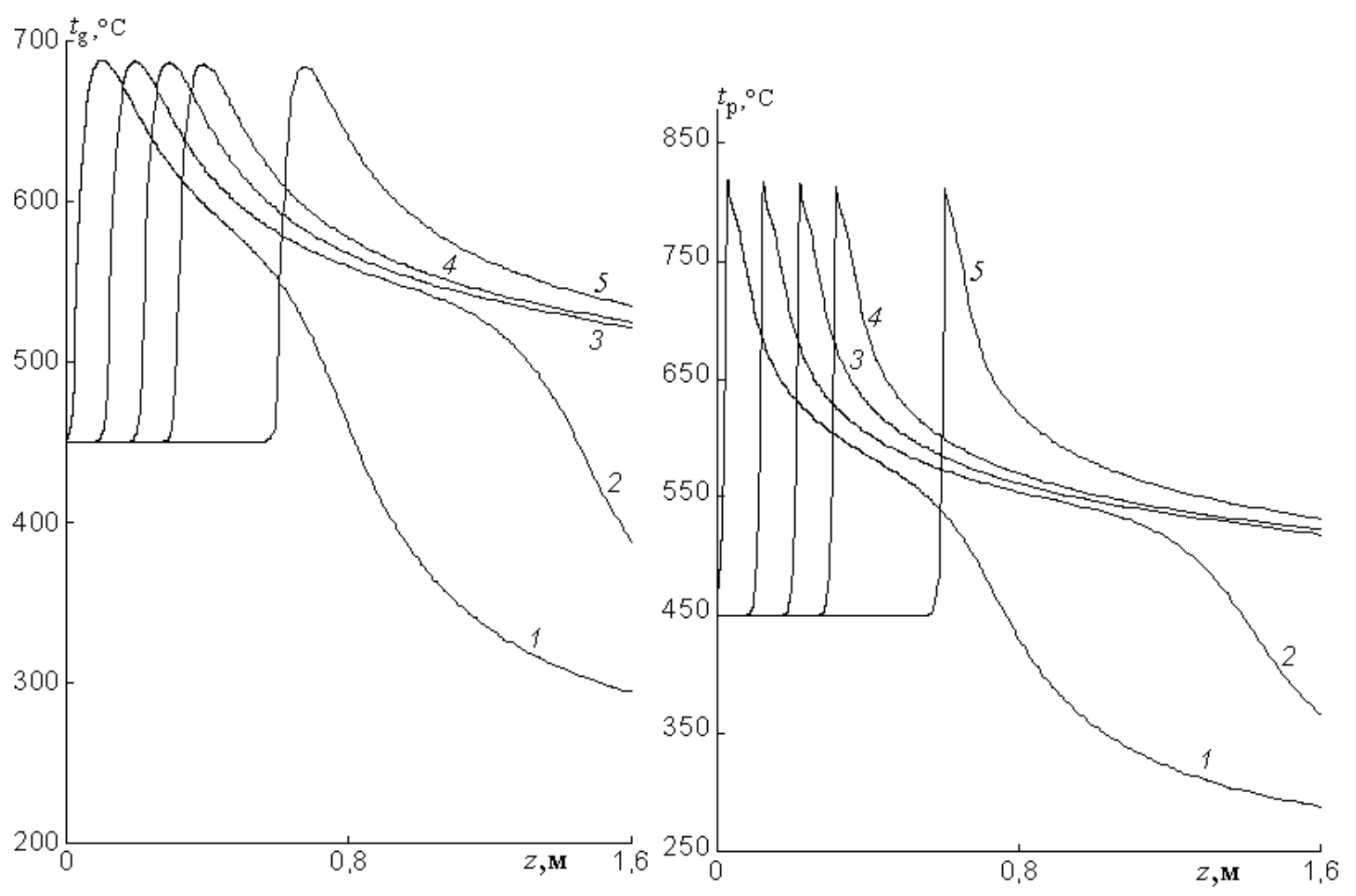

Рис. 2. Распределение температур газа и частиц торфа по высоте неподвижного слоя в зависимости от времени при отношении массовых долей компонентов парокислородной смеси $\mathrm{H}_{2} \mathrm{O} / \mathrm{O}_{2}=70 / 30$ : $1-30 \mathrm{c} ; 2-70 \mathrm{c} ; 3-111 \mathrm{c} ; 4-151 \mathrm{c} ; 5-272 \mathrm{c}$.

Fig 2. Temperature distribution of the gas and peat particles over the height of the fixed bed as a function of time when the ratio of the mass fractions of the components of the vapor-oxygen mixture $\mathrm{H}_{2} \mathrm{O} / \mathrm{O}_{2}=70 / 30$ : $1-30 \mathrm{~s} ; 2-70 \mathrm{~s} ; 3-111 \mathrm{~s} ; 4-151 \mathrm{~s} ; 5-272 \mathrm{~s}$. 


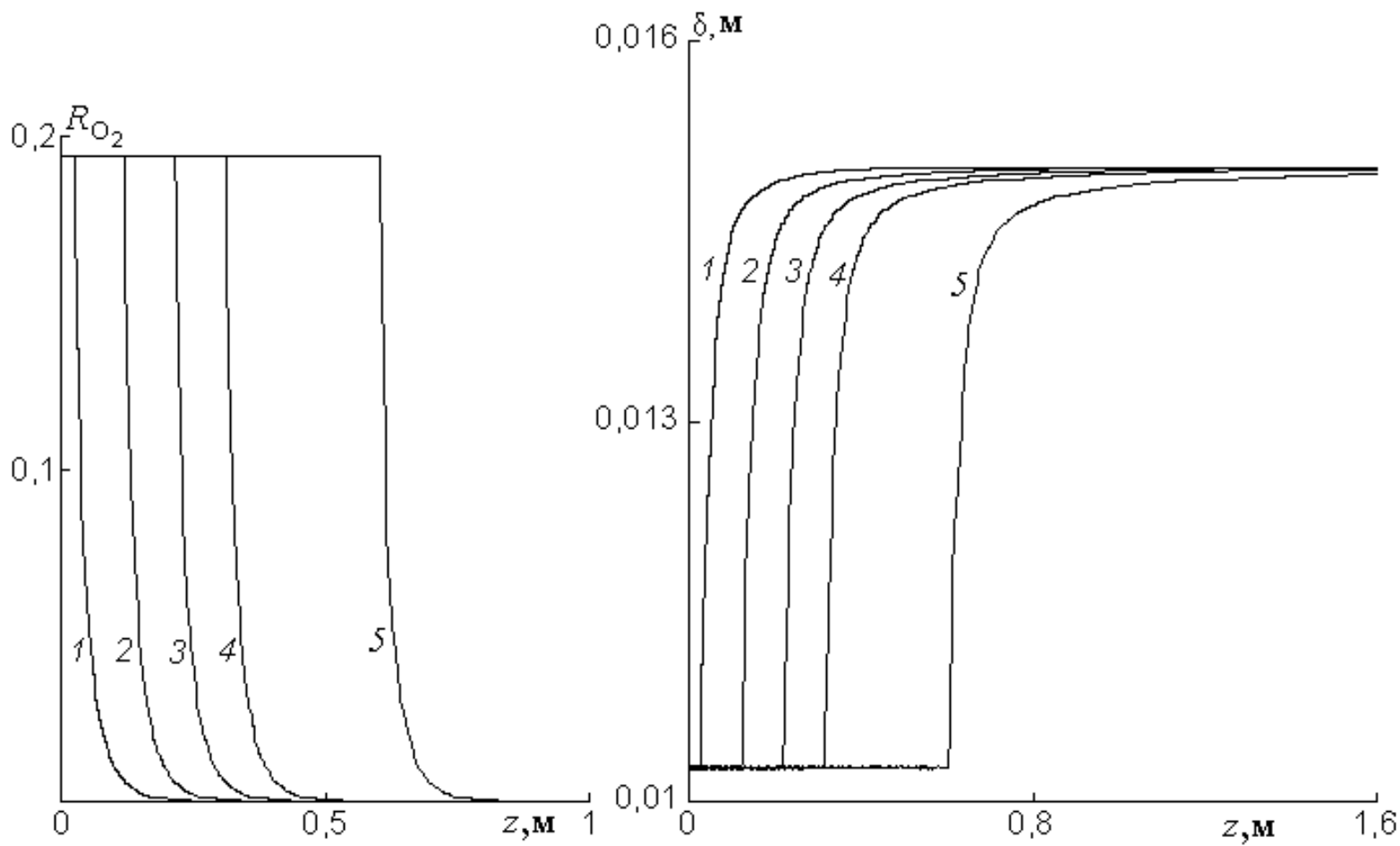

Рис. 3. Распределение объемной доли кислорода и диаметра частиц по высоте неподвижного слоя в зависимости от времени при отношении массовых долей парокислородной смеси $\mathrm{H}_{2} \mathrm{O} / \mathrm{O}_{2}=\mathbf{7 0 / 3 0}$ (обозначения те же, что на рис. 2).

Fig. 3. Distribution of the volume fraction of oxygen and the particle diameter over the height of the fixed bed as a function of time with a ratio of the mass fractions of an oxygen-oxygen mixture $\mathrm{H}_{2} \mathrm{O} / \mathrm{O}_{2}=\mathbf{7 0 / 3 0}$ (notations are the same as in Fig. 2).
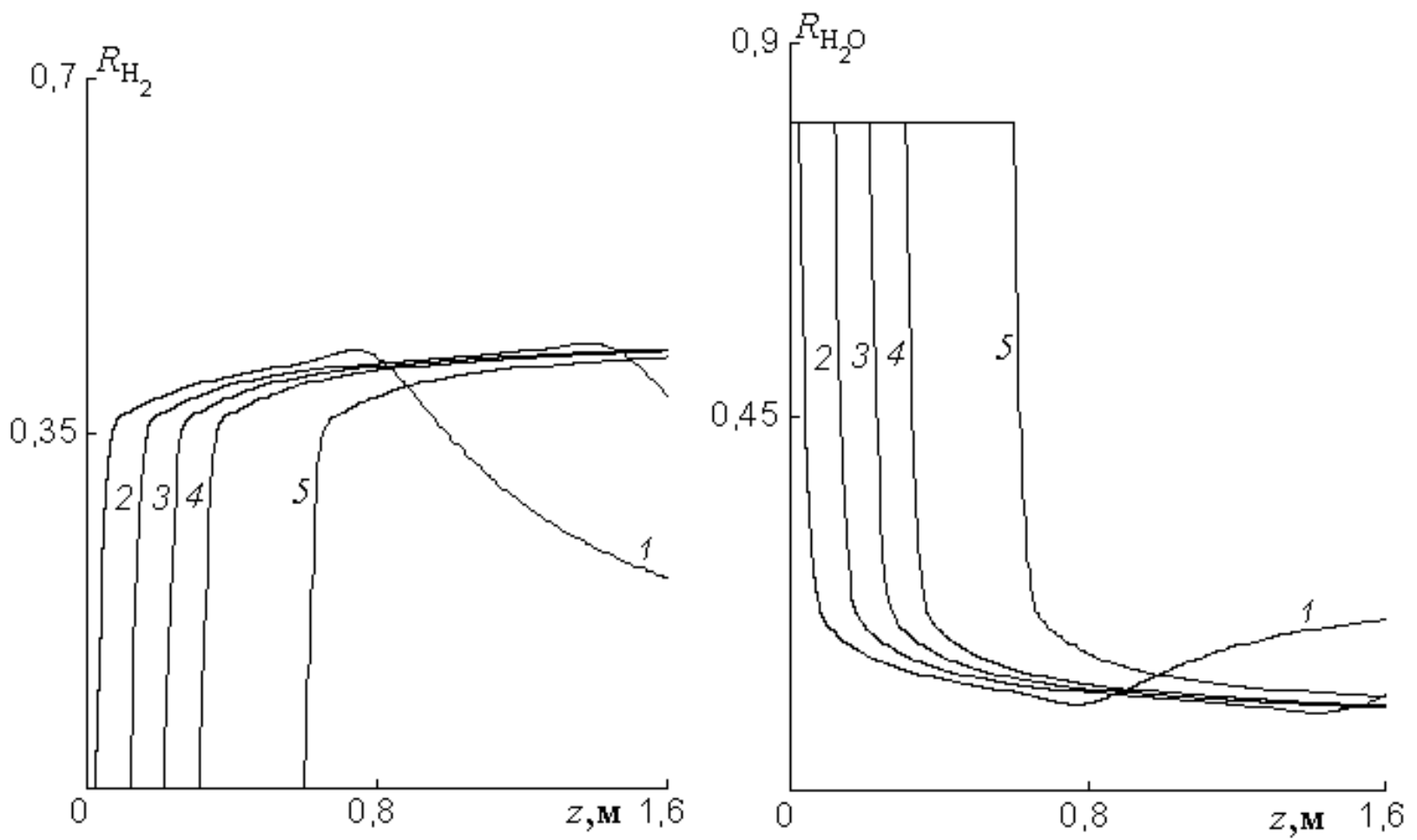

Рис. 4. Распределение объемных долей компонентов газа $\mathrm{H}_{2}$ и $\mathrm{H}_{2} \mathrm{O}$ по высоте неподвижного слоя в зависимости от времени при отношении массовых долей парокислородной смеси $\mathrm{H}_{2} \mathrm{O} / \mathrm{O}_{2}=70 / 30$ (обозначения те же, что на рис. 2).

Fig. 4. Volume fractions distribution of the gas components $\mathrm{H}_{2}$ and $\mathrm{H}_{2} \mathrm{O}$ over the height of the fixed bed as a function of time with a ratio of the mass fractions of the vapor-oxygen mixture $\mathrm{H}_{2} \mathrm{O} / \mathrm{O}_{2}=\mathbf{7 0 / 3 0}$ (notations are the same as in Fig. 2). 

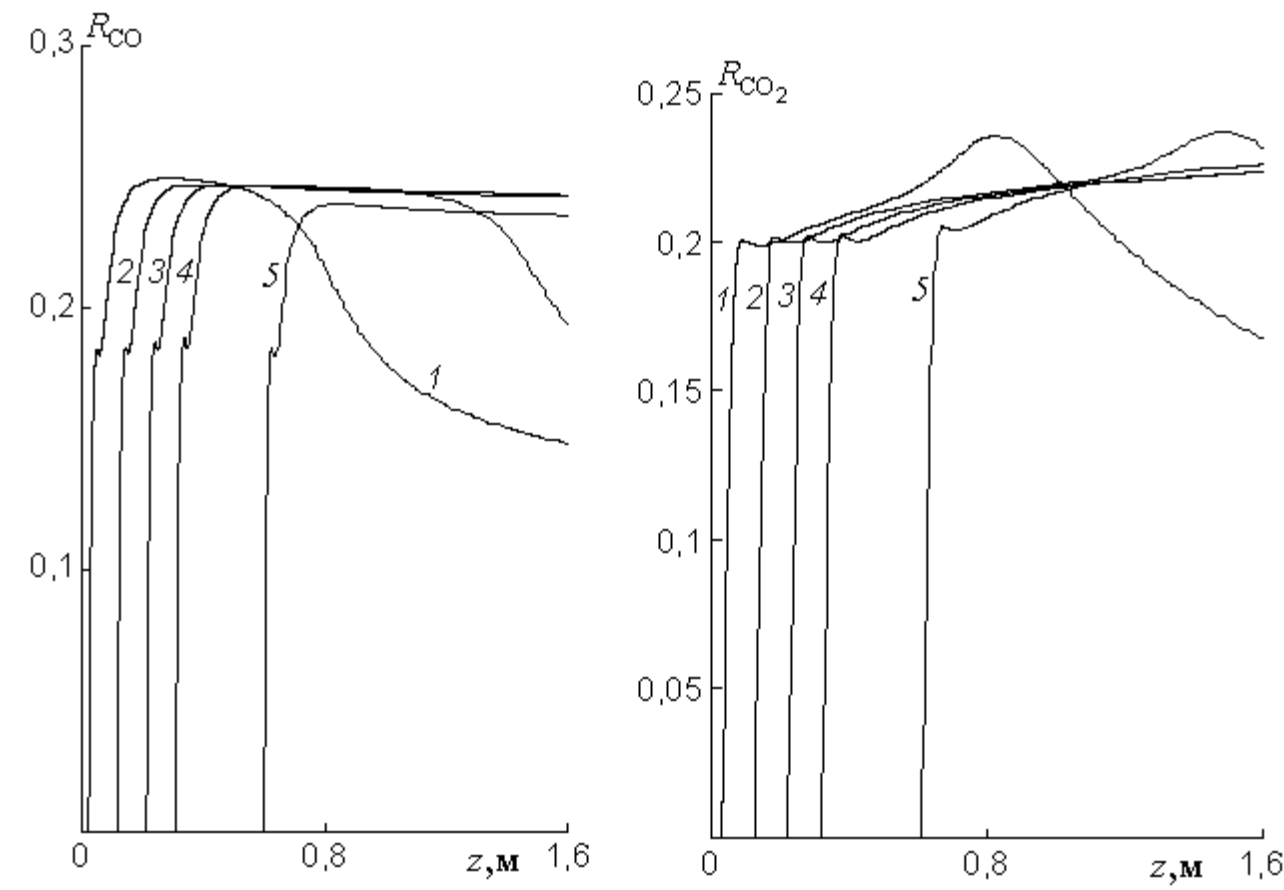

Рис. 5. Распределение объемных долей компонентов газа СО2 и СО по высоте неподвижного слоя в зависимости от времени при отношении массовых долей парокислородной смеси $\mathrm{H}_{2} \mathrm{O} / \mathrm{O}_{2}=70 / 30$ (обозначения те же, что на рис. 2).

Fig. 5. Volume fractions distribution of the gas components $\mathrm{CO}_{2}$ and $\mathrm{CO}$ over the height of the fixed bed as a function of time with a ratio of the mass fractions of the vapor-oxygen mixture $\mathrm{H}_{2} \mathrm{O} / \mathrm{O}_{2}=\mathbf{7 0 / 3 0}$ (notations are the same as in Fig. 2).

В этом интервале происходит убывание функции $\delta(\tau, z)$ из-за конверсии частиц торфа за счет гетерогенных реакций, благодаря чему диаметр дискретной фазы уменьшается с $\delta=10,69$ мм до минимального размера частиц $\delta_{\text {ash }}$ $=10,3$ мм, состоящих из золы (рис. 3 , кривая 1 ). Полученный таким образом инертный материал формирует шлаковую подушку (поз. 2 на рис. 1), которая защищает колосники от перегрева.

Во втором интервале (окислительновосстановительная область реагирования) 0,028 м $<z<0,1036$ м, где объемная доля $\mathrm{O}_{2}$ падает до $1 \%$, теплопоглощение эндотермических реакций превосходит тепловыделение экзотермических реакций. В результате значения $t_{\mathrm{p}}$ и $R_{\mathrm{H}_{2} \mathrm{O}}$ снижаются до $704,1^{\circ} \mathrm{C}$ и $19,9 \%$, объемные доли $\mathrm{CO}_{2}, \mathrm{CO}$ и $\mathrm{H}_{2}$ продолжают возрастать и достигают величин 19,98 \%, 22,25 \% и 36,9\%, соответственно, а диаметр частиц уменьшается с 14,53 мм до 10,69 мм.

В бескислородной восстановительной зоне 0,1036 м $<z<0,693$ м, где температура частиц торфа и объемная доля водяного пара уменьшаются до $494,6{ }^{\circ} \mathrm{C}$ и $10,96 \%$, наблюдается слабый рост значений функций $R_{\mathrm{CO}_{2}}(\tau, z)=22,66 \%$ и $R_{\mathrm{H}_{2}}(\tau, z)=42,9 \%$, в то время как зависимость $R_{\text {СО }}(\tau, z)$ в точке $z=0,29$ м достигает своего максимального значения 24,94 \%. На участке 0,29 м $<z<0,693$ м кривая $R_{\mathrm{CO}}(\tau, z)$ убывает до величины $23,4 \%$. Такое поведение зависимостей $R_{\mathrm{CO}_{2}}(\tau, z), R_{\mathrm{H}_{2}}(\tau, z)$ и $R_{\mathrm{CO}}(\tau, z)$ связано с протеканием химических реакций $\mathrm{C}+\mathrm{CO}_{2}=2 \mathrm{CO}$, $\mathrm{C}+\mathrm{H}_{2} \mathrm{O}=\mathrm{CO}+\mathrm{H}_{2}$ и $\mathrm{CO}+\mathrm{H}_{2} \mathrm{O} \rightarrow \mathrm{CO}_{2}+\mathrm{H}_{2}$. В рассматриваемой области за счет гетерогенных восстановительных реакций отмечается уменьшение размера частиц торфа с 15 мм до 14,53 мм.

Конвективный теплообмен между твердой и газовой фазами и тепловыделение гомогенных химических реакций $\mathrm{CO}+0,5 \mathrm{O}_{2}=\mathrm{CO}_{2}$ и $\mathrm{H}_{2}+0,5 \mathrm{O}_{2}=\mathrm{H}_{2} \mathrm{O}$ обеспечивают резкое возрастание кривой $t_{\mathrm{g}}(\tau, z)$ с $450{ }^{\circ} \mathrm{C}$ до максимального значения $687,8^{\circ} \mathrm{C}$ (рис. 2 , кривая 1 ).

Видно, что зависимости $t_{\mathrm{p}}(\tau, z)$ и $t_{\mathrm{g}}(\tau, z)$ подобны, однако максимум кривой $t_{\mathrm{g}}(\tau, z)$ сдвинут вверх по вертикальной оси $z$ на 72 мм относительно максимума функции $t_{\mathrm{p}}(\tau, z)$.

В зоне пиролиза 0,693 м < $z<1,61$ м (поз. 5, рис. 1) происходит, нагрев сухой дискретной фазы до температуры $287,5-494,6{ }^{\circ} \mathrm{C}$ (рис. 2, кривая 1) за счет межфазного конвективного теплообмена и радиационно-кондуктивного теплопереноса в твердой фазе, что обеспечивает интенсивный выход летучих веществ из частиц торфа. В результате этого наблюдается рост зависимостей $R_{\mathrm{CH}_{4}}(\tau, z)$ и $R_{\mathrm{C}_{2} \mathrm{H}_{2}}(\tau, z)$ (рис. 6 а, кривые 1,3 ). 

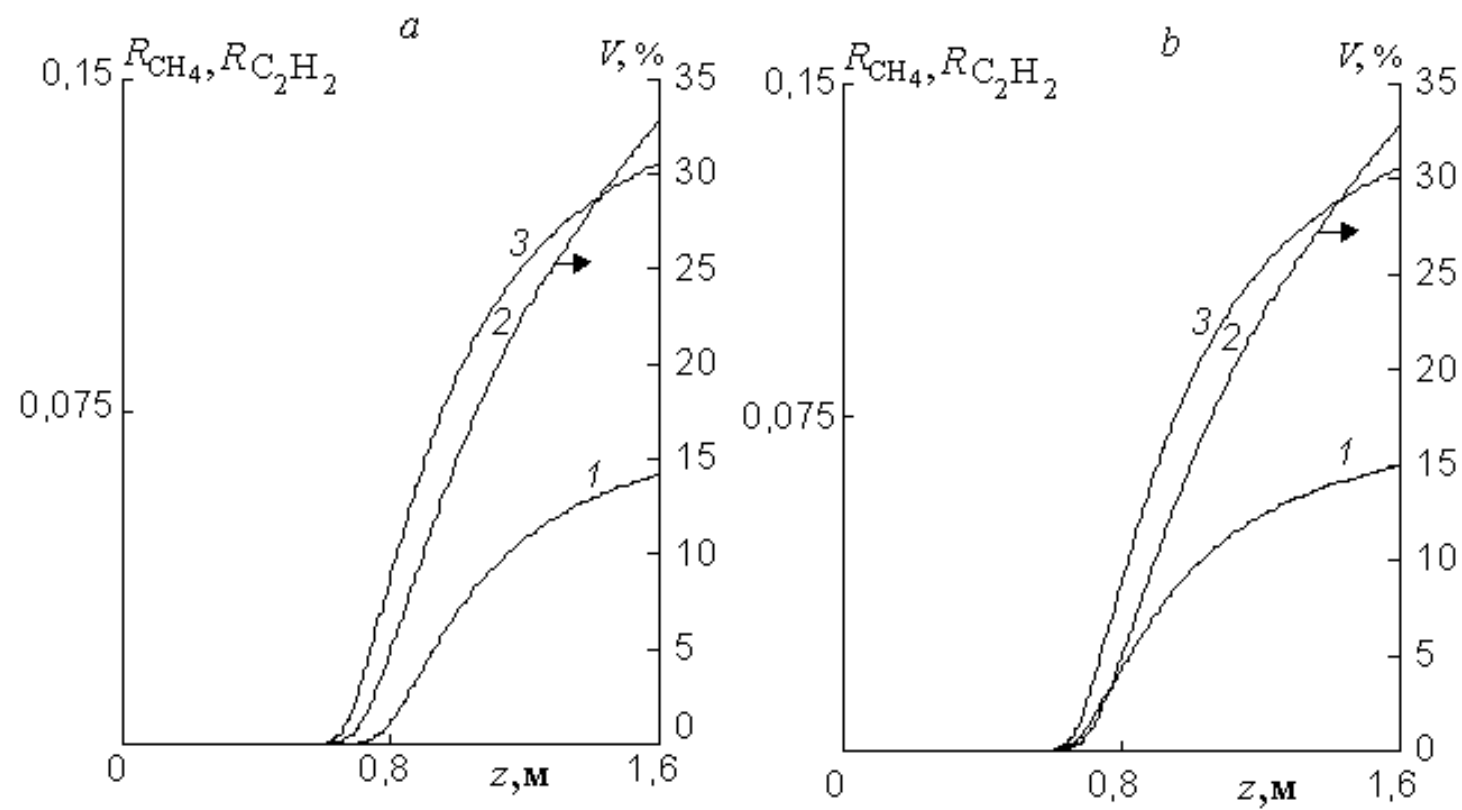

Рис. 6. Распределение объемных долей компонентов газа $\mathrm{CH}_{4}, \mathrm{C}_{2} \mathrm{H}_{2}$ и летучих веществ по высоте неподвижного слоя в момент времени 30 с при отношении массовых долей парокислородной смеси $\mathrm{H}_{2} \mathrm{O} / \mathrm{O}_{2}=70 / 30(a)$ и $\mathrm{H}_{2} \mathrm{O} / \mathrm{O}_{2}=40 / 60$ (b): $1-\mathrm{C}_{2} \mathrm{H}_{2} ; 2-V ; 3-\mathrm{CH}_{4}$.

Fig. 6. Volume fractions distribution of the gas components $\mathrm{CH}_{4}, \mathrm{C}_{2} \mathrm{H}_{2}$ and volatiles by the height of the fixed bed at time 30 $\mathrm{s}$ with a ratio of mass fractions of oxygen-vapor mixture $\mathrm{H}_{2} \mathrm{O} / \mathrm{O}_{2}=70 / 30(\boldsymbol{a})$ and $\mathbf{H}_{2} \mathrm{O} / \mathrm{O}_{2}=\mathbf{4 0 / 6 0}(\boldsymbol{b}): 1-\mathrm{C}_{2} \mathrm{H}_{2} ; 2-V ; 3-\mathrm{CH}_{4}$

Следует обратить внимание на характер поведения кривых $R_{\mathrm{CO}}(\tau, z), R_{\mathrm{CO}_{2}}(\tau, z), R_{\mathrm{H}_{2}}(\tau, z)$ и $R_{\mathrm{H}_{2} \mathrm{O}}(\tau, z)$ в рассматриваемом диапазоне (рис. 4 и рис. 5, кривые 1). В интервале 0,693 м $<z<0,824$ м объемные доли $\mathrm{CO}_{2}$ и $\mathrm{H}_{2}$ достигают максимальных значений $R_{\mathrm{CO}_{2}}(\tau, z)=23,56 \%$ и $R_{\mathrm{H}_{2}}(\tau, z)=$ $=43,15 \%$, в то время как зависимости $R_{\text {Со }}(\tau, z)$ и $R_{\mathrm{H}_{2} \mathrm{O}}(\tau, z)$ монотонно убывают до величин $21 \%$ и $10,46 \%$, соответственно. Такое поведение можно объяснить протеканием реакции водяного сдвига $\mathrm{CO}+\mathrm{H}_{2} \mathrm{O} \rightarrow \mathrm{CO}_{2}+\mathrm{H}_{2}$. На участке $0,824 \mathrm{~m}<z<1,61$ м наблюдается уменьшение значений функций $R_{\mathrm{CO}}(\tau, z), R_{\mathrm{CO}_{2}}(\tau, z)$ и $R_{\mathrm{H}_{2}}(\tau, z)$ и возрастание зависимости $R_{\mathrm{H}_{2} \mathrm{O}}(\tau, z)$. Такое поведение кривых обусловлено разложением кислородосодержащего комплекса $\mathrm{CH}_{2,71311} \mathrm{O}_{0,982248} \rightarrow 0,211773 \mathrm{CO}+$ $+0,134764 \mathrm{CO}_{2}+0,333524 \mathrm{CH}_{4}+0,162893 \mathrm{C}_{2} \mathrm{H}_{2}+$ $0,0256683 \mathrm{H}_{2}+0,500946 \mathrm{H}_{2} \mathrm{O}$. Из этого следует, что объемные доли метана и водяного пара значительно больше, чем водорода, диоксида и оксида углерода. Поэтому при смешении компонентов летучих веществ с компонентами газа, выходящего из зоны газификации (поз. 4 на рис. 1), происходит уменьшение величин $R_{\mathrm{CO}}, R_{\mathrm{CO}_{2}}, R_{\mathrm{H}_{2}}$ и возрастание значения $R_{\mathrm{H}_{2} \mathrm{O}}$. В области сухой перегонки плотность частиц торфа уменьшается за счет выхода летучих веществ при неизменном диаметре дисперсной фазы (см. (12)).

Кроме того с увеличение времени высота шлаковой подушки возрастает $\left(\Delta z_{\text {ash }}(\tau=70 \mathrm{c})=\right.$ $=104 \mathrm{мm}, \Delta z_{\text {ash }}(\tau=272 \mathrm{c})=602$ мм), вследствие чего зоны окисления, газификации и пиролиза смещаются вверх по вертикальной оси $z$ (рис. 2, ср. кривые 1 и 5). Здесь скорость перемещения окислительной зоны оказывается значительно меньше, чем скорость убывания летучих веществ по высоте слоя. По этой причине выгорания компонентов пиролизных газов и кислородосодержащего соединения $\mathrm{CH}_{2,71311} \mathrm{O}_{0,982248}$ не происходит. Например, при $\tau=30$ с зона окисления располагается на участке $0<z<0,1036$ м, в то время как область, содержащая летучие вещества, находится в диапазоне 0,693 м $<z<1,61$ м, т.е. эти области не пересекаются (рис. 3, кривая 1; рис. $6 a$, кривая 2). Таким образом, состав генераторного газа на выходе из реактора необходимо рассматривать как сумму синтетического газа результата конверсии фиксированного углерода и пиролизного газа.

С течением времени количество летучих веществ в дискретной фазе фиксированного слоя уменьшается (при $0<\tau \leq 30$ с в сечении $z=1,61 \mathrm{M}$ количество летучих снизилось с $V_{\max }^{\mathrm{d}}=61,25 \%$ до $32,86 \%$ (рис. $6 a$, кривая 2)), вследствие чего состав генераторного газа на выходе из реактора 
будет изменятся, о чем свидетельствуют данные, приведенные в таблице. Видно, что в интервале 0 $<\leq 70$ с и $V>0$ состав генераторного газа на выходе из реактора значительно изменяется. В диапазоне $\tau>70$ с и $V \rightarrow 0$ продукт газификации изменяется незначительно.
В варианте 1 в зоне максимальных тепловыделений температура частиц торфа не превышает $818,5{ }^{\circ} \mathrm{C}$ и оказывается ниже, чем температура начала деформации золы $t_{\mathrm{A}}=1140{ }^{\circ} \mathrm{C}$, что позволяет организовать режим газификации в реакторе с твердым шлакоудалением.

Таблица 1. Объемные доли компонентов генераторного газа на выходе из реактора.

Table 1. Volume fractions of the generator gas components at the outlet of the reactor.

\begin{tabular}{|c|c|c|c|c|c|c|c|}
\hline Время, с & $\begin{array}{c}\mathrm{CH}_{2,71311} \\
\mathrm{O}_{0,982248},\end{array}$ & $\begin{array}{c}\mathrm{H}_{2} \\
\%\end{array}$ & $\begin{array}{c}\mathrm{CO}_{2} \\
\%\end{array}$ & $\begin{array}{c}\mathrm{CO} \\
\%\end{array}$ & $\begin{array}{c}\mathrm{CH}_{4} \\
\%\end{array}$ & $\begin{array}{c}\mathrm{C}_{2} \mathrm{H}_{2} \\
\%\end{array}$ & $\begin{array}{c}\mathrm{H}_{2} \mathrm{O} \\
\%\end{array}$ \\
\hline \multicolumn{7}{|c|}{ Вариант 1} \\
\hline 10 & 18,82 & 7,66 & 11,08 & 11,76 & 16,63 & 8,11 & 25,92 \\
\hline 30 & 8,63 & 20,71 & 16,68 & 14,81 & 12,48 & 6,09 & 20,6 \\
\hline 70 & 1,24 & 38,77 & 23,03 & 19,4 & 4,08 & 1,99 & 11,48 \\
\hline 110 & - & 43,28 & 22,35 & 24,34 & - & - & 10,04 \\
\hline 210 & - & 42,82 & 22,57 & 23,78 & - & - & 10,84 \\
\hline \multicolumn{7}{|c|}{} & \multicolumn{7}{|c|}{ Вариант 2} & & \\
\hline 10 & 16,4 & 2,26 & 7,48 & 15,91 & 17,68 & 8,63 & 31,63 \\
\hline 30 & 5,69 & 11,57 & 6,56 & 35,89 & 13,1 & 6,39 & 20,79 \\
\hline 70 & - & 27,32 & 1,5 & 71,02 & - & - & 0,153 \\
\hline 110 & - & 27,23 & 1,31 & 71,4 & - & - & 0,0572 \\
\hline 210 & - & 26,83 & 1,79 & 70,96 & - & - & 0,405 \\
\hline
\end{tabular}

В варианте 2 для повышения эффективности рабочего процесса (калорийности и качества генераторного газа) массовая доля $\mathrm{O}_{2}$ была увеличена с $30 \%$ до $60 \%$, а $\mathrm{H}_{2} \mathrm{O}$ - уменьшена с $70 \%$ до $40 \%$ по сравнению с вариантом 1 , вследствие чего температура частиц в окислительной зоне возросла с $t_{\mathrm{p}, \max 1}=818,5^{\circ} \mathrm{C}$ до $t_{\mathrm{p}, \max 2}=1590{ }^{\circ} \mathrm{C}$ и стала превалировать над температурой жидкоплавкого состояния золы $t_{\mathrm{C}}=1350{ }^{\circ} \mathrm{C}$. Это позволяет построить режим термохимической переработки торфа с устойчивым жидким шлакоудалением (рис. 2 и рис. 7 , кривые 2).

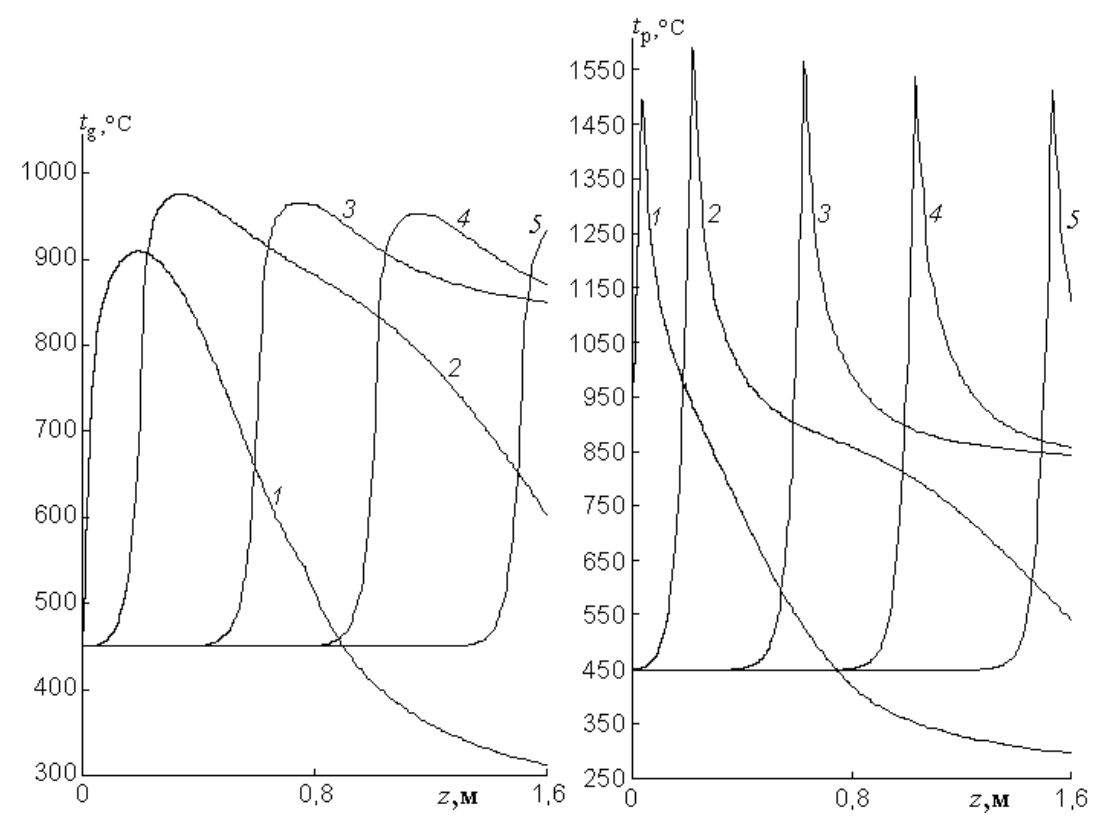

Рис. 7. Распределение температур газа и частиц по высоте неподвижного слоя в зависимости от времени при отношении массовых долей компонентов парокислородной смеси Н2О/О2 = 40/60: 1 - 30 c; 2 - 70 с; 3 - 151 с; 4 - 232 с; 5 $333 \mathrm{c}$.

Fig. 7. Temperature distribution of gas and particles along the height of the fixed bed depending on the time with a ratio of mass fractions of the vapor-oxygen mixture components $\mathbf{H}_{\mathbf{2}} \mathbf{O} / \mathbf{O}_{\mathbf{2}}=\mathbf{4 0 / 6 0}: 1-30 \mathrm{~s} ; 2-70 \mathrm{~s} ; 3-151 \mathrm{~s} ; 4-232 \mathrm{~s} ; 5-333 \mathrm{~s}$. 
В даной работе приведено сравнительный анализ вариантов: 1) скорости гомогенных и гетерогенных реакций в варианте 2 значительно выше, чем в первом, благодаря чему скорость перемещения верхней границы шлаковой подушки в варианте 2, больше, чем в варианте 1 , несмотря на тот факт, что $\delta_{02}>\delta_{01}\left(\Delta z_{\text {ash } 1}(\tau=272 \mathrm{c})\right.$

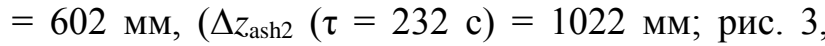
кривая 5 и рис. 8 , кривая 4$) ; 2$ ) состав синтетического газа в варианте $1(\tau>70 \mathrm{c})$ характеризуется большим содержанием балласта $\mathrm{CO}_{2}=22,4 \%$ и $\mathrm{H}_{2} \mathrm{O}=10,3 \%$ и сравнительно низкой объемной долей горючей части $-\mathrm{CO}+\mathrm{H}_{2}=67,4 \%$, в отличие от второго $(\tau>30 \mathrm{c})-\mathrm{CO}_{2}=1,5-2 \%$, $\mathrm{H}_{2} \mathrm{O}=0,1-0,6 \%$ и $\mathrm{CO}+\mathrm{H}_{2}=98 \%$ (рис. 4 , рис. 5 и рис. 9, рис. 10 , кривые 3,4$) ; 3$ ) хотя скорость перемещения окислительной зоны по высоте слоя в варианте 2 значительно выше, чем в первом, однако ее недостаточно для взаимодействия окис- лительной области с зоной сухой перегонки, вследствие чего здесь не происходит окисление пиролизных газов (при $\tau=30$ с: окислительная зона $-0<z<0,298$ м, зона сухой перегонки $0,611 \mathrm{~m}<z<1,61 \mathrm{~m}$; рис. 8 , кривая 1 ; рис. $6 \mathrm{~b}$, кривая 2); 4) подобно варианту 1 во втором временной интервал $0<\tau<210$ с можно условно разделить на две области (см. табл.). В первой из них $0<\tau \leq 30$ с и $V>0$ состав генераторного газа на выходе из реактора существенно изменяется. Во второй области $\tau>30$ с летучие вещества в дискретной массе слоя отсутствуют, поэтому объемные доли компонентов синтетического газа изменяются незначительно; 5) несмотря на вышеизложенные преимущества второго варианта над первым, реализация варианта 2 требует больших капитальных затрат и более сложной организации и управления рабочим процессом, чем в варианте 1.
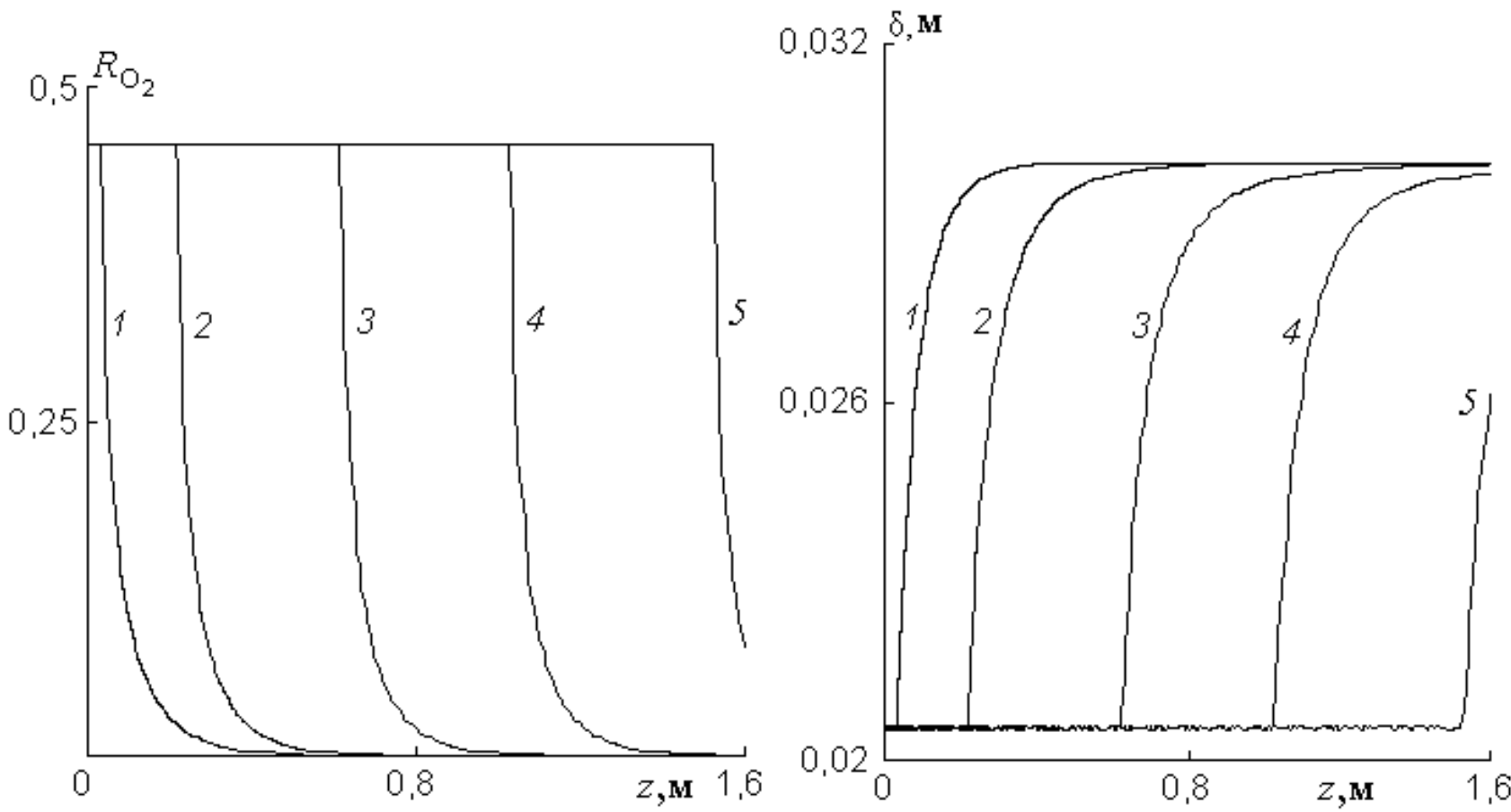

Рис. 8. Распределение объемной доли кислорода и диаметра частиц по высоте неподвижного слоя в зависимости от времени при отношении массовых долей парокислородной смеси $\mathrm{H}_{2} \mathrm{O} / \mathbf{O}_{2}=\mathbf{4 0 / 6 0}$ (обозначения те же, что на рис. 7).

Fig. 8. Volume fraction distribution of oxygen and the particle diameter over the height of the fixed bed as a function of time with a ratio of the mass fractions of an oxygen-oxygen mixture $\mathrm{H}_{2} \mathrm{O} / \mathrm{O}_{2}=\mathbf{4 0 / 6 0}$ (notations are the same as in Fig. 7). 

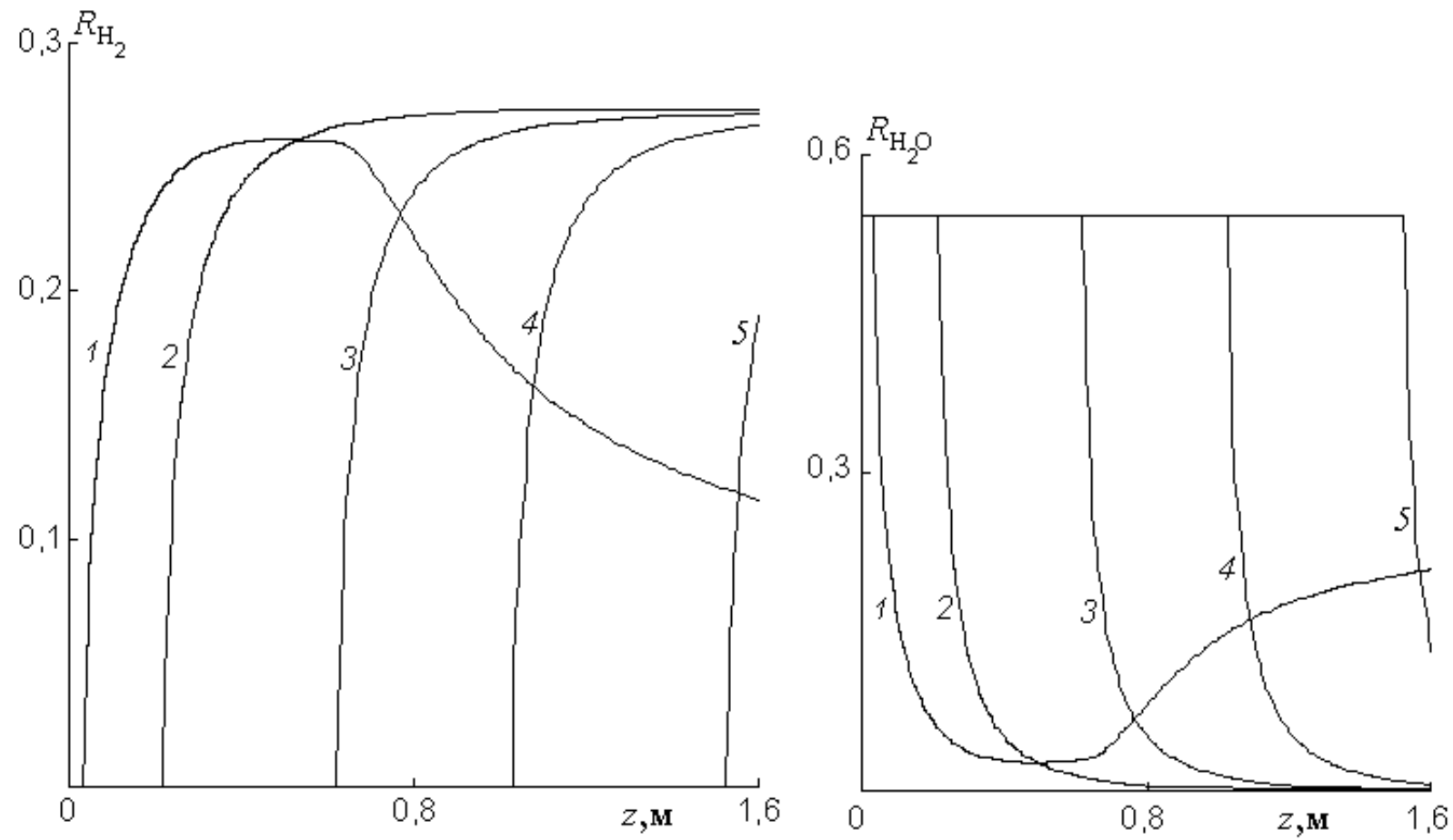

Рис. 9. Распределение объемных долей компонентов газа Н2 и $\mathrm{H}_{2} \mathrm{O}$ по высоте неподвижного слоя в зависимости от времени при отношении массовых долей парокислородной смеси $\mathrm{H}_{2} \mathrm{O} / \mathrm{O}_{2}=\mathbf{4 0 / 6 0}$ (обозначения те же, что на рис. 7).

Fig. 9. Volume fraction distribution of the gas components $\mathrm{H}_{2}$ and $\mathrm{H}_{2} \mathrm{O}$ over the height of the fixed bed as a function of time with a ratio of the mass fractions of the oxygen-oxygen mixture $\mathrm{H}_{2} \mathrm{O} / \mathrm{O}_{2}=\mathbf{4 0 / 6 0}$ (notations are the same as in Fig. 7).
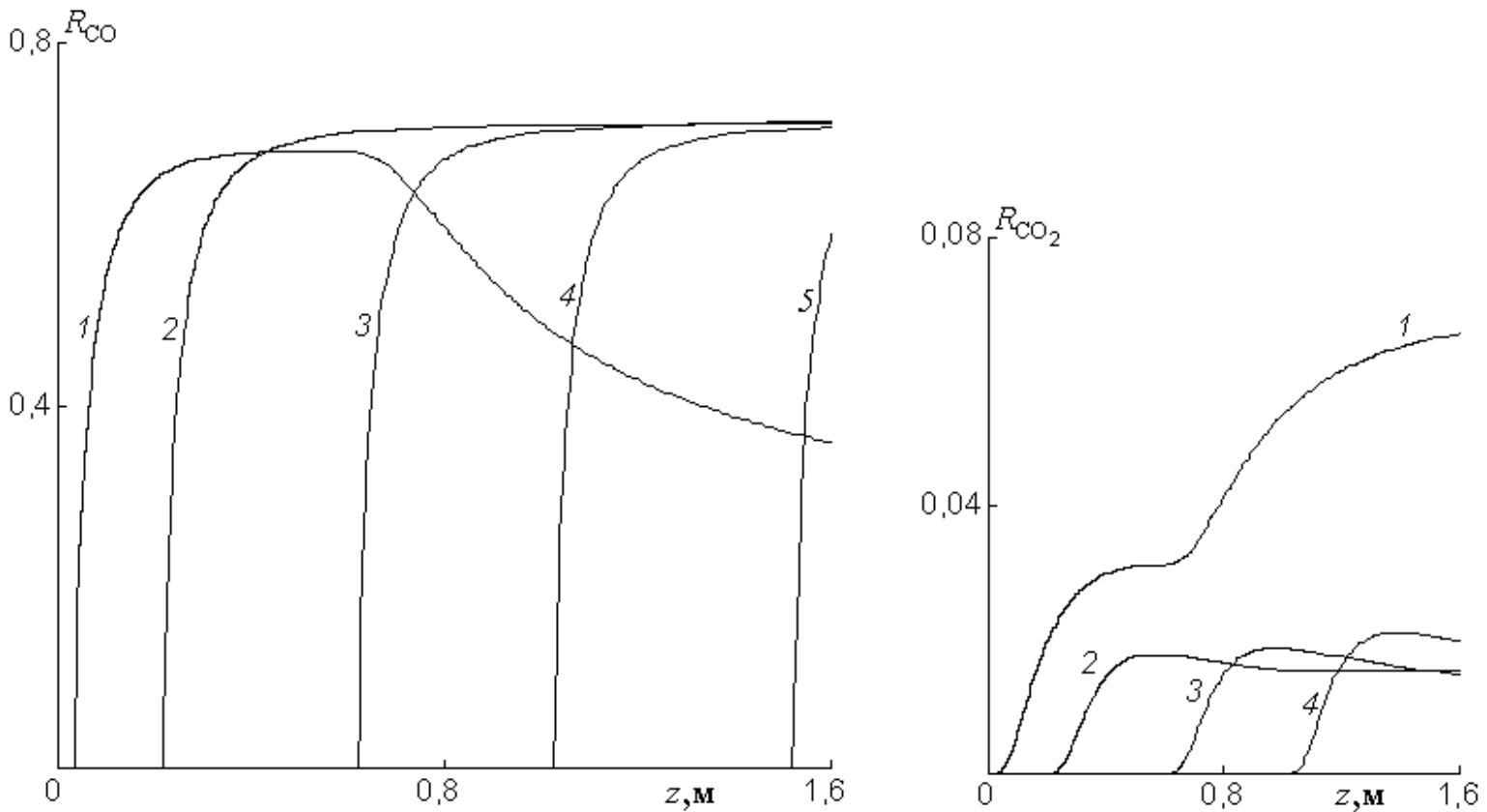

Рис. 10. Распределение объемных долей компонентов газа $\mathrm{CO}_{2}$ и СО по высоте неподвижного слоя в зависимости от времени при отношении массовых долей парокислородной смеси $\mathrm{H}_{2} \mathrm{O} / \mathrm{O}_{2}=\mathbf{4 0 / 6 0}$ (обозначения те же, что на рис. 7).

Fig. 10. Volume fraction distribution of the gas components $\mathrm{CO}_{2}$ и $\mathrm{CO}$ over the height of the fixed bed as a function of time with a ratio of the mass fractions of the oxygen-oxygen mixture $\mathrm{H}_{2} \mathrm{O} / \mathrm{O}_{\mathbf{2}}=\mathbf{4 0 / 6 0}$ (notations are the same as in Fig. 7). 
Выводы. 1. Предложенная модель позволяет получить детальную информацию о геометрических, аэродинамических, тепловых и физикохимических параметрах парокислородной газификации твердого топлива под давлением в неподвижном слое в любой момент времени. Эта информация может быть использована при конструировании реакторов на стадиях эскизного, технического и рабочего проектирования, пусконаладочных режимах и работе газогенератора на различных нагрузках, когда процесс парокислородной газификации торфа является нестационарным из-за цикличности подачи исходного топлива и выгрузки золы при помощи системы шлюзовых бункеров.

2. Показано, что: а) основной процесс газификации частиц торфа в варианте 1 происходит в окислительно-восстановительной зоне, благодаря чему температура дискретной фазы и содержание $\mathrm{H}_{2} \mathrm{O}$ снижаются с $818,5{ }^{\circ} \mathrm{C}$ и $72,84 \%$ до $704,1{ }^{\circ} \mathrm{C}$ и $19,9 \%$; б) в бескислородной восстановительной зоне состав генераторного газа слабо изменяется, поэтому рассматриваемая область является малоэффективной; в) скорость перемещения окислительной зоны по оси $z$ значительно меньше, чем скорость убывания летучих веществ по высоте слоя, вследствие чего выгорания компонентов пиролизных газов не происходит. По этой причине состав генераторного газа на выходе из реактора необходимо рассматривать как сумму синтетического (из-за конверсии фиксированного углерода) и пиролизного газов; г) в варианте 1 температура частиц торфа не превышает $818,5^{\circ} \mathrm{C}$ и оказывается ниже, чем температура начала деформации золы $1140{ }^{\circ} \mathrm{C}$, что позволяет построить режим газификации с твердым шлакоудалением. Для повышения эффективности рабочего процесса (калорийности и качества генераторного газа) в варианте 2 массовая доля $\mathrm{O}_{2}$ была увеличена, а $\mathrm{H}_{2} \mathrm{O}$ - уменьшена по сравнению с первым, вследствие чего температура частиц в окислительной зоне возросла с $t_{\mathrm{p}, \max 1}=818,5{ }^{\circ} \mathrm{C}$ до $t_{\mathrm{p}, \max 2}=$ $=1590{ }^{\circ} \mathrm{C}$, что создает благоприятные условия для устойчивого вытекания жидкого шлака из газификатора; д) в варианте 1 генераторный газ имеет большое содержание балласта $\mathrm{CO}_{2}=22,4 \%$ и $\mathrm{H}_{2} \mathrm{O}$ $=10,3 \%$ и сравнительно низкую долю горючей части $-\mathrm{CO}+\mathrm{H}_{2}=67,4 \%$, в отличие от второго $\mathrm{CO}_{2}=1,5-2 \%, \mathrm{H}_{2} \mathrm{O}=0,1-0,6 \%$ и $\mathrm{CO}+\mathrm{H}_{2}=98,4 \%$.
1. Рохман Б.Б. Двумерная модель процесса газификации твердого топлива в неподвижном слое под давлением. 1. Исследование конверсии шубаркольского каменного угля в парокислородной смеси при отношении массовых долей $\mathrm{H}_{2} \mathrm{O} / \mathrm{O}_{2}=45 / 55$. Відновлювана енергетика. 2019. № 1. С. 61-71.

\section{REFERENCES}

1. Rokhman B.B. Dvumernaya model processa gazifikacii tverdogo topliva $\mathrm{v}$ nepodvizhnom sloe pod davleniem. 1. Issledovanie konversii shubarkolskogo kamennogo uglya $\mathrm{v}$ parokislorodnoj smesi pri otnoshenii massovyh dolej $\mathrm{H}_{2} \mathrm{O} / \mathrm{O}_{2}=45 / 55$. [Two-dimensional model of solid fuel gasification in a fixed bed under pressure. 1. Investigation conversion of Shubarkol coal conversion in a steam-oxygen mixture with the mass past of $\left.\mathrm{H}_{2} \mathrm{O} / \mathrm{O}_{2}=45 / 55\right]$. Vidnovluvana energetika. 2019. No. 1. Pp. 6171. [in Russian]

\section{МАТЕМАТИЧНИЙ ОПИС ПРОЦЕСУ ГАЗИФІКАЦІЇ ТВЕРДОГО ПАЛИВА В ФІКСОВАНОМУ ШАРІ: 1. ЧИСЕЛЬНІ РЕЗУЛЬТАТИ ТЕРМОХІМІЧНОЇ ПЕРЕРОБКИ ТОРФУ В ПАРОКИСНЕВІЙ СУМІШІ ПІД ТИСКОМ 3 МПа}

\section{Б.Б. Рохман, доктор технічних наук}

Інститут відновлюваної енергетики НАН України, 02094, вул. Гната Хоткевича, 20А, м. Київ, Україна,

Побудовано систему параболічних рівнянь, щзо описує нестаиіонарний прочес аеродинаміки, тепломасообміну і хімічного реагування твердого палива (частинк торфу або біомаси) в парокисневій суміші в нерухомому шарі з урахуванням конвективного теплообміну між газом і дисперсною фазою, радіаційно-кондуктивного теплопереносу твердої фази, променистого і кондуктивного теплообміну частинок шару зі стінкою реактора, гетерогенних і гомогенних хімічних реакцій, сил тяжіння і аеродинамічного опору. На підставі отриманої системи рівнянь розроблені алгоритм і програма, з використанням якої отримано детальну інформацію про розподіл основних параметрів робочого прочесу термохімічної переробки торфу під тиском 3 МПа в залежності від часу для двох варіантів: при співвідношенні масових часток в парокисневій суміші $\mathrm{H}_{2} \mathrm{O} / \mathrm{O}_{2}=70 / 30 \mathrm{i}$ $\mathrm{H}_{2} \mathrm{O} / \mathrm{O}_{2}=40 / 60$. Проведено порівняльний аналіз цих варіантів. Показано, шьо: а) в першому варіанті $\mathrm{H}_{2} \mathrm{O} / \mathrm{O}_{2}=70 / 30$, де в зоні максимальних тепловиділень температура частинок торфу виявлясться нижчою, ніж температура початку деформації золи, організовується режим газифікаиії з твердим шилаковидаленням. У другому $-\mathrm{H}_{2} \mathrm{O} / \mathrm{O}_{2}=40 / 60$ за раху нок високої інтенсифікаиії процесу температура твердої фази в окислювальній зоні значно перевищує температуру жидкоплавкого стану золи, що дозволяє організувати режим газифікаиії торфу зі стійким витіканням рідкого шлаку з газогенератора; б) варіант 1 характеризується високим вмістом баласту в синтетичному газі $\mathrm{CO}_{2}=22,4 \% \mathrm{i}$ $\mathrm{H}_{2} \mathrm{O}=10,3 \%$ і порівняно низькою об'ємною часткою горючої частини - $\mathrm{CO}+\mathrm{H}_{2}=67,4 \%$, в порівнянні з варіантом 2 $\mathrm{CO}_{2}=1,5-2 \%, \mathrm{H}_{2} \mathrm{O}=0,1-0,6 \%$ і $\mathrm{CO}+\mathrm{H}_{2}=98 \%$. Бібл. 1, табл. 1, рис.10.

Ключові слова: нерухомий шар, торф, теплопровідність, парокиснева газифікаиія, кондуктивний, радіаційний, темnepaтура. 